\title{
LA MÚSICA AL SEMINARI DE TORTOSA
}

\author{
Mn. Josep Alanyà I RoIG
}

\begin{abstract}
This article analyses the treatment and ever-growing importance of liturgical music, Gregorian chant and religious polyphonic music, as well as the culture of popular and civilian music in the Tortosian Diocesan Seminar for the fifty years of its existence. The great musical tradition of this Tortosian institution is highlighted by following the life and works of musicians and musicologists such as Felip Pedrell, Father Vicent Ripollés, Father Josep $\mathrm{M}^{\mathrm{a}}$ Peris and Father Vicent Garcia Julbe. We can also learn what the nourishment and conditions for the birth and development of Professor Josep Pavia as a musicologist and priest were from the early years of his youth.
\end{abstract}

\section{Resum}

Aquest article analitza el tractament i la importància creixent de la música litúrgica, el cant gregorià, la música sagrada polifònica i també del conreu de la música popular i profana al Seminari Diocesà de Tortosa durant els cinquanta anys de la seva existència. Es posa en evidència la gran tradició musical d'aquesta institució tortosina seguint el fil de la vida $\mathrm{i}$ obra de músics i musicòlegs com Felip Pedrell, Vicent Ripollés, Mn. Josep M ${ }^{a}$ Peris i Mn. Vicent Garcia Julbe. I es dóna a conèixer quin va ser l'humus i el nodriment del Dr. Josep Pavia com a musicòleg i prevere de l'Església des dels anys de la seva adolescència.

Al Seminari Diocesà de Tortosa, la Música ha brillat sempre amb llum pròpia de constel·lació perquè ja des del principi es conrearen amb molt de gust, dedicació i sentit artístic tant el cant figurat i polifònic, litúrgic, profà i popular, com el cant litúrgic gregorià. La tradició musical entre els seminaristes i sacerdots, a Tortosa, venia de lluny i les arrels d'aquesta tradició eren plantades en aquell ric camp, el propi Seminari, que havia sembrat de bells sons i harmonies, de músiques inspirades davant el sagrari i l'altar, el gran sacerdot i músic que fou el beat Josep $\mathrm{M}^{\mathrm{a}}$ Peris i Polo (1889-1936), rector del Seminari Conciliar de Tortosa de 1916 a 1926. La seva música eucarística, mariana i josefina, també la popular i folklòrica, ressonava tot sovint pels àmbits dels patis, capelles i església. Era la música inconfusible de Mn. Peris. Música que havia conreat en vida amb la seva inspiració i òptima tècnica i que havia regat en mort, amb la pròpia sang vessada per Jesucrist Summe Sacerdot el 1936.

La fecunditat de la vida espiritual amarada de música de Mn. Peris seguí donant fruits de solemnitat i bellesa, d'espiritual devoció eucarística i sacerdotal, en el nou Seminari Diocesà de l'Assumpció, fundat i erigit pel bisbe Manuel Moll i Salord (1897-1972), aixecat damunt un turó 
que domina la vall de l'Ebre i la ciutat de Tortosa i construït entre els anys 1945 i 1958 . El mestratge musical de $\mathrm{Mn}$. Josep $\mathrm{M}^{\mathrm{a}}$ Peris havia esdevingut l'anella de la cadena que lligava el mestratge del seu mestre, Mn. Vicent Ripollés i Pérez (1867-1943), amb el del seu deixeble, Mn. Vicent Garcia Julbe (1903-1997). Millor baula no la podia haver.

Ripollés, Peris i Garcia Julbe són tres compositors preveres de la diòcesi de Tortosa que omplen un segle llarg de la història religiosa i musical del bisbat tortosí i de l'Església amb llur música engendrada des del Seminari, composta per al Seminari i interpretada per la Schola Cantorum del Seminari. Són tres generacions de músics i quatre generacions de seminaristes cantors que han constituït amb llurs creacions musicals i interpretacions acurades la joia i el prestigi del Seminari Diocesà. Vides de músics que estan plenament lligades i en gran part són també paral-leles: tots tres eren valencians, de terres de Castelló, preveres de la diòcesi de Tortosa, deixebles un de l'altre i els tres compositors. Al darrere de tots tres hi ha l'impuls poderós del compositor i musicòleg tortosí Felip Pedrell (1841-1922), deixeble al seu torn del Mestre de Capella de la Seu tortosina Joan Antoni Nin i Serra. ${ }^{1}$

Mn. Vicent Ripollés, nascut a Castelló de la Plana el 1867, era alumne del nostre Seminari i, ordenat prevere, hi fou Mestre de Capella com ho fou també de la Catedral, nomenat el 1893. El 1895 obtingué el mateix càrrec al Col·legi del Corpus Christi de València, fundat pel Patriarca Sant Joan de Ribera, passant després a la Catedral de Sevilla i retornant finalment, el 1930, a la Seu de València. Escriví una Missa en re menor per a 4 veus i orgue, una Missa a 7 veus per a cinc instruments de corda i orgue i moltes altres obres musicals polifòniques. Col·laborà al prestigiós «Boletín de la Sociedad Castellonense de Cultura» amb diverses publicacions: Fragmentos del Epistolario Pedrell (1922), Catálogo de las obras polifónicas conservadas en el Archivo del Patriarca de Valencia (1926), El drama litúrgico (1928), El villancico i la cantata del segle XVIII a València (1935) i Músicos castellonenses (1935). Realitzà així mateix moltes transcripcions de música polifònica del segle XVI. ${ }^{2}$

Mn. Josep Ma Peris (1889-1936) fou alumne del Col·legi de Sant Josep de Tortosa i va ser ordenat de prevere com a membre de la Germandat de Sacerdots Operaris del Sagrat Cor de Jesús a la Catedral de Tortosa el 6 de juny de 1914 pel bisbe Pedro Rocamora y García. De molt jove destacà en dots musicals i en coneixements que aprengué ja del seu pare, i tocava el cornetí a la banda municipal de Cinctorres (Ports de Morella) abans d'entrar al Col·legi de Sant Josep. Durant els anys d'estudis eclesiàstics seguí conreant la música i el cant gregorià, i destacà com a organista, compositor i director de cants i de cor rebent els ensenyaments del Mestre de Capella de la Catedral de Tortosa Mn. Eduard Torres. Després de l'ordenació de prevere fou enviat a

1. Joan Antoni Nin i Serra (1804-1867) havia estat nen cantor de l'escolania de la Seu de Barcelona, on es formà, i allí es familiaritzà amb la música del Mestre de Capella de la Seu barcelonina Francesc Valls (1671 c.-1747). Cfr. Josep Pavia I Simó, La música en Cataluña en el siglo XVIII. Francesc Valls, CSIC, Barcelona, 1997. Nin i Serra ocupava la plaça de Mestre de Capella de la Seu tortosina l'any 1824 i la serví fins a la seva mort. L'any que moria el mestre Nin i Serra naixia a Castelló el mestre Vicent Ripollés. L'any 1872 naixia a Albaida Mn. Eduard Torres, qui fou Mestre de Capella de la Catedral de Tortosa de 1895 fins a 1910 que anà com a Mestre de Capella a la Catedral de Sevilla, morint en aquesta ciutat el 1937. En els anys d'estada a Tortosa formà musicalment el jove seminarista Josep $\mathrm{M}^{\mathrm{a}}$ Peris.

2. Montserrat Albet, entrada «Ripollés i Pérez, Vicent», a Gran Enciclopèdia Catalana, 12, p. 625. 
València durant uns mesos per tal de perfeccionar els seus estudis de música amb el sacerdot castellonenc i canonge de la Seu valentina Mn. Vicent Ripollés. Fou nomenat director del Col·legi de Sant Josep de Tortosa i rector del Seminari Conciliar de 1916 a 1926, rector del de Còrdova de 1926 a 1932, i rector del de Barcelona de 1933 a 1936. El 15 d'agost de 1936 fou arrabassat de la seva casa pairal, a Cinctorres, per ser afusellat i donar la seva vida en testimoniatge i defensa del Crist i pel fet de ser sacerdot, estroncant-se així una vida exemplar i tota la seva tasca creadora, d'una trajectòria força interessant i valuosa, en l'àmbit musical.

La vivència sacerdotal i la pietat eucarística i mariana que caracteritzaren Mn. Peris eren la font de la seva inspiració musical. Les hores a la capella dels seminaris on fou educador i rector, davant el sagrari i la imatge de la Mare de Déu, eren hores de pregària profunda que adobaven la seva espiritualitat i les seves facultats de compositor. Així és que li devem les Avemaries, la Felicitació Sabatina, la Felicitació Josefina i els múltiples cants eucarístics i sacerdotals d'entre els quals sobresurt l'Haec est dies. En la seva faceta de pedagog compongué i edità mètodes de solfeig i de cant gregorià per a ús dels seminaristes: Lecciones graduadas de Canto Coral. Primero y segundo cursos. Lecciones graduadas de Canto Coral. Tercero y cuarto cursos. Lecciones de Canto Gregoriano. Aquestes obres eren editades per la Germandat de Sacerdots Operaris a Ediciones Sígueme de Salamanca.

Mn. Ramon Boix, canonge de la Seu de Tortosa i cinctorrà com Mn. Peris, a qui conegué i tractà de jovenet, ha escrit aquestes notes biogràfiques:

«En música gregoriana se formó temporalmente en Marendsous (Bélgica), en Solesmes (Francia) e incluso en Besalú (Gerona). Fueron sus maestros: su conocidísimo Felipe Pedrell y los franceses Duran y Dubois. Y, en contrapunto, Cumellas Ribó, seglar, conocidísimo y extraordinario organista de la iglesia de Pompeya (Barcelona).

Aquí no pretendo demostrar la perfección técnica ni la belleza musical ni hacer la lista de sus composiciones. Su intención y propósito en componer fue siempre la mejor formación litúrgica, pastoral y piadosa de los seminaristas; y que tuvieran para ello el instrumento oportuno. "Cuanto hizo en plan de formación musical y literaria no tenía, en su concepto, más que un carácter subsidiario de la misión e ideal substancial de formador de futuros sacerdotes" (Juan de Andrés, Testigos de su Sacerdocio, 1990, p. 560). Temas eucarísticos, marianos y josefinos que aumentaban la devoción de los colegiales serían interpretados en las comunidades parroquiales apoyando así la pastoral piadosa. ¡Cuántos domingos por las tardes, después del gregoriano de las Vísperas, en nuestras iglesias se oía la piadosa música de Mn. Peris! Y muchos sacerdotes lograron de su compañero Rector del Seminario la composición de himnos y gozos para sus comunidades cristianas respectivas.

Los seminaristas eran estimulados pastoralmente a aprender canto para que, después, ya sacerdotes, ensayaran a sus fieles y crearan, en muchos pueblos Coros Parroquiales que dignificaran el culto litúrgico y devocional. Sería hermoso y ejemplarizante escribir la "Historia de los Coros Parroquiales" y la "Música Religiosa-popular" de nuestra Diócesis de Tortosa: descubriríamos tiempos y personas pastoralmente a imitar. Mosén Peris fue un paladín. Como anécdota curiosa: "los cincuenta duros, premio del concurso ganado por el himno a la Santa Cinta (Tortosa), los invirtió en adquirir un armonium digno para la capilla del Colegio" (Juan de Andrés, op. cit., p. $562)$. 
Referente a su maestría en música suscitó amor al canto en la Liturgia y en los ejercicios devocionales del Colegio y de las Parroquias. Ayudó a quienes tenían disposiciones naturales al canto, la composición y la dirección.» ${ }^{3}$

I un d'ells, sense dubtes el seu millor alumne i el preferit del mestre, preparat musicalment a la seva imatge i semblança, fou aquell seminarista de Vinaròs que es deia Vicent Garcia Julbe.

Mn. Vicent Garcia Julbe nasqué a Vinaròs el 15 d'agost de 1903. Als vuit anys estudiava solfeig i violí a l'Acadèmia de Música del Cercle Catòlic, amb el professor Mn. Josep Antolí, beneficiat de la parròquia de l'Assumpció de Vinaròs. Als onze anys ingressà al Seminari Conciliar de Tortosa i quedà sota la protecció i orientació del Beat Mn. Josep Maria Peris, aleshores superior i director de música del Seminari i des de 1916 fins a 1926 també rector. Fou ell qui descobrí en el jove Vicent Garcia el talent i coneixements musicals de què era dotat i li ensenyà piano, orgue, harmonia i composició, esdevenint en els seus darrers anys de Seminari el continuador del mestre en la labor docent musical.

Mn. Boix ha escrit del Beat Josep $\mathrm{M}^{\mathrm{a}}$ Peris i de la seva relació amb Mn. Garcia Julbe:

«Pero de quien fue maestro, y él se considera único discípulo, es del M. Iltre. D. Vicente García Julbe, Canónigo-Prefecto de Música Sacra (hoy Maestrescuela) de la S. I. Catedral B. de Tortosa y Profesor emérito de nuestro Seminario. Natural de Vinaroz (1903) lo tuvo de Prefecto de Latinos y Director en Filosofía y Teología. Le moduló la voz; le puso de organista (1919); luego de maestro de Capilla; y le enseñó composición, armonía y contrapunto; incluso, por correspondencia, durante las vacaciones.

Su máxima para componer piezas religiosas fue: «Antes de componer vete al Sagrario; allí te inspirarás» (García Julbe). No procede buscar una melodía de composición sino unir la letra y la música arrodillado ante el Sagrario, meditando y orando.» ${ }^{4}$

L'any 1926, Mn. Vicent Garcia Julbe, ja molt ensinistrat per Mn. Peris en els coneixements musicals teòrics i pràctics, completà els seus estudis de composició a Barcelona amb el mestre Josep Cumellas i Ribó (Gràcia, Barcelona 1857-1940), qui havia estat ja mestre de Mn. Peris. Cumellas i Ribó era compositor i organista. Deixeble d'Enric Granados, fou organista de l'església de Sant Felip Neri, de Gràcia, i del convent dels caputxins de Pompeia, i des del 1926, director musical de Ràdio Barcelona. Membre de la Germanor d'Orfeons de Catalunya, fundà l'Orfeó Gracienc i l'Orfeó Montserrat. Fou autor de sarsueles catalanes com La torre (1898), El recomanat (1899), Montserrat (1907) i de la música escènica per a Muntanyes blanques (1911), de Juli Vallmitjana. Harmonitzà nombroses cançons populars catalanes i és autor d'obres corals de sardanes, d'obres per a orgue, per a piano, i de cançons infantils per a cant i piano. ${ }^{5} \mathrm{Mn}$. Garcia Julbe estudià musicologia amb el mestre Mn. Vicent Ripollés, canonge de València i alumne predilecte de Felip Pedrell.

3. Ramón Boix Querol, M. Iltre. D. José María Peris Polo, O.D., Rector de Seminario (1889-1936), Lliçó inaugural del curs 1993-94, Seminari de Tortosa, 1994, pp. 22-23.

4. Ibidem, p. 22.

5. Montserrat Albet, entrada «Cumellas i Ribó, Josep» a Gran Enciclopèdia Catalana, 5, p. 823. 
El mes de març de 1927, a punt de ser ordenat de prevere, es presentà a les oposicions a Mestre de Capella de la Catedral de Tarragona i obtingué el segon lloc d'entre els cinc opositors que s'hi havien presentat. L'oposició fou guanyada per Mn. Francesc Tàpies i Torres (18981985), qui havia estat Mestre de Capella de la Catedral de Lugo.

El mes de juny de 1928, ja ordenat de prevere pel Bisbe Fèlix Bilbao, guanyà les oposicions a Mestre de Capella de la Catedral de Lugo, plaça que havia deixat vacant el canonge Tàpies. A Lugo hi sojornà tretze anys, del 1928 al 1941, essent alhora director del cor del Seminari i de la Coral Lucense. Després passà a Lleida per ocupar el càrrec de Mestre de Capella de la Catedral. L'any 1941 era bisbe administrador apostòlic de Lleida Mons. Manuel Moll i Salord, coadjutor de Tortosa amb dret a successió a la seu tortosina a la mort del bisbe Fèlix Bilbao i Ugarriza. El bisbe Moll, ja bisbe residencial de Tortosa, cridarà Mn. Garcia Julbe a Tortosa i el farà canonge de la Seu uns anys més tard.

Essent la seva aspiració de treballar en la transcripció dels grans fons musicals del segle XVI existents al Col·legi i Capella del Patriarca de València, on havia estat Mestre de Capella el seu mestre Mn. Vicent Ripollés, Mn. Vicent Garcia oposità i guanyà la plaça de director de la Capella del Patriarca el 1942. Durant set anys, del 1942 al 1949, exercí amb gran encert i prestigi aquest càrrec i realitzà les transcripcions de les Villanescas de Francisco Guerrero (Sevilla 1528-1599) i de les Danzas del Santísimo Corpus Christi de Joan Baptista Comes (València 1582?-1643). Preparà així mateix una extensa Antologia d'obres del segle XVI, de les quals publicà el primer volum.

El 1949 fou nomenat pel bisbe Manuel Moll Canonge Prefecte de Música Sacra de la Catedral de Tortosa i encarregat de la formació musical del Seminari Diocesà. La Schola Cantorum del Seminari, formada i preparada amb molta exigència i perfecció per Mn. Jaume Sirisi i Escoda, la trobà Mn. Vicent Garcia a punt per fer-ne una agrupació coral d'un altíssim nivell i gran prestigi. Així fou i ha estat reconegut. Mn. Joan Ramon Herrero i Llidó, que fou deixeble de Mn. Garcia Julbe i membre de la Schola Cantorum, i ha estat fundador de la Coral Vicent Ripollés, de Castelló, ha escrit: «La Schola Cantorum del Seminario alcanza, bajo su dirección, un enorme prestigio, realizando distintos conciertos y participando en las solemnidades litúrgicas de la Catedral.» ${ }^{6}$

Continuant la seva labor d'investigació realitzà la col·lecció completa de les obres anomenades Jacobeas del segle XVII, dels fons musicals de la catedral de Sant Jaume de Galícia. Al mateix temps transcrivia la Música Barroca de la Catedral de Tortosa, especialment la relativa a la Mare de Déu de la Cinta i a l'Assumpció. Per tota la seva labor la Ciutat de Tortosa li fou reconeguda i li atorgà la distinció «Dert Ilerca» al Mèrit Pro Arte.

Jubilat de les seves classes de Teologia i Música al Seminari es traslladà a viure de Tortosa a Vinaròs, la seva vila nadiua, on fins a la seva mort, el 25 d'agost de 1997, seguí treballant

6. Joan Ramon Herrero Llidó, a Programa de mà del Concierto - Homenage al M. Iltre. D. Vicente García Julbe, 1 de maig de 1984, celebrat al Seminari Diocesà, p. 2. Mn. Joan Ramon Herrero i Llidó, amb la Coral Vicent Ripollés, ha estat un dels grans difusors de la música de Mn. Vicent Garcia Julbe. Joan Ramon Herrero, deixeble de Mn. Garcia, havia nascut a Artana el 6 de febrer de 1933, ingressà al Seminari de Tortosa, on exercí d'organista i hi fou ordenat el 24 de juny de 1956 i morí a Castelló de la Plana, servint a la música de la Concatedral de Santa Maria, el 13 d'agost de 1997. 
en la recerca musicològica en noves obres clàssiques espanyoles. L'any 1984 fou honorat amb el nomenament de Prelat Domèstic de Sa Santedat.

Mn. Vicent Garcia era membre col-laborador de l'Institut Espanyol de Musicologia del Consell Superior d'Investigacions Científiques, publicant dos volums, el 1955 i 1957, a Monumentos de la Música Española, obra revisada i prologada pel musicòleg Miguel Querol. Com a membre del «Instituto Valenciano de Musicología Alfonso el Magnánimo» publicà el volum Danzas del Santísimo Corpus Christi de J. B. Comes. Era també membre de l'Institut d'Estudis Tarraconenses «Ramon Berenguer IV», de la Diputació de Tarragona.

De la seva obra escriu Joan Ramon Herrero i Llidó: «Son innumerables las composiciones que ha realizado en el transcurso de su vida. Se recuerda principalmente la «Missa Jubilaris» a seis voces y órgano que fue interpretada en la Arciprestal de Vinaròs por la Coral del Seminario de Tortosa en 1960, con motivo del 350 aniversario de la llegada de la Reliquia de San Sebastián a esta ciudad.» ${ }^{7}$

Tota l'excel-lència musical de les composicions de Mn. Vicent Garcia anà sempre acompanyada indefectiblement de la pietat i bondat espiritual -no oblidà el consell de Mn. Peris-, de la inquietud artística i tècnica, de l'afany de recerca i neguit innovador, del profund fonament musicològic i compositiu que arrelava en el substrat de Pedrell passant pel subsòl de Mn. Peris i Mn. Vicent Ripollés, i sobretot d'una gran humilitat, una de les mares d'aquesta excel·lència musical de l'obra de Mn. Vicent Garcia. I la prova de la humilitat la tenim en les seves partitures originals sempre escrites a llapis, fet que les ha convertides en obra delicada i fràgil. Per això les partitures originals a llapis, per tal que no es perdessin, havien de ser passades després a tinta per alguns seminaristes que formaven part de la Schola. Recordem Manuel Monferrer i Agut, qui solia passar a tinta la lletra, i Josep Pavia i Simó, qui solia passar a tinta la música i a voltes també la lletra.

De la humilitat de Mn. Garcia Julbe hi ha una bona anècdota que en dóna fe. L'ha conservat en la seva ment i en el seu cor fidelment el Dr. Mn. Josep Pavia, el nostre homenatjat. En un dels assaigs de la «Cantata In Dedicatione Ecclesiae», a 4 v. m., piano i orgue, en acabar-se 1'assaig Mn. Vicent Garcia aixecà de l'atril els papers de la partitura, escrita a llapis, i tot mostrantlos digué: «Restos del Diluvio». Mn. Josep Pavia se li apropà i li oferí de fer-li tota una partitura nova escrita a tinta, cosa que el director acceptà gratament. En presentar-li la nova partitura copiada i tornar-li l'original a llapis, Mn. Pavia, referint-se a la partitura original, li preguntà: «I què en faig, d'això?». Resposta de Mn. Vicent Garcia: «Crema-ho!» Mn. Josep Pavia, emèrit musicòleg del Consell Superior d'Investigacions Científiques a Barcelona, guardà la partitura original i avui, amb ciència i consciència del compositor, la conserva com un ric tresor en el seu arxiu.

De l'extensa producció musical de Mn. Vicent Garcia Julbe, gairebé tota realitzada durant la seva estada a Tortosa i estrenada per la Schola Cantorum del Seminari, que ell dirigia i que elevà a tan alt nivell i prestigi, l'Arxiu del Seminari Diocesà guarda les partitures originals següents:

7. Ibídem, p. 2. Cfr. etiam Ramon Miravall i Dolç, entrada "Garcia i Julve. Vicent", a Diccionari d'història e'clesiàstica de Catalunya, II, p. 247. 
1. Fiat misericordia, a 7 v. m.

2. Caenantibus illis, a 4 v. i.

3. Justus ut palma, a $4 \mathrm{v} . \mathrm{m}$.

4. Salmo 18. Himno latréutico a Dios Creador y Legislador. La Gloria de Yahvé, a 5 v. m.

5. Salm 46. Jubilate Deo, a 5 v. m. i orgue.

6. Dios te salve, a 4 v. i. i orgue.

7. Dextera Domini, a 4 v. i.

8. Tantum ergo, a 4 v. i.

9. Sacerdotes Domini, a 4 v. m.

10. Gloria, laus, a 4 v. m.

11. Salmo 99. Aclamad a Yahvé, a 3 v. m. i orgue.

12. Publiquen festivos, partitura per a piano.

13. Publiquen festivos, per a veus i orgue (a llapis).

14. Miserere, a 4 v. m.

15. Sacerdos et Pontifex, a 4 v. m.

16. Te Deum, 4 v. m. i orgue (partitura original a llapis i partitures de les diferents veus).

17. Tu es Petrus, a 4 v. m., harmònium i piano.

18. Posuisti, Domine, in capite eius. Ofertorio para la misa de un mártir, a 4 v. m. i orgue.

19. Agnus Dei, a 4 v. i.

20. Partitura a llapis sense identificar, a $4 \mathrm{v}$. i.

21. Tota pulchra, a 2 cors i 6 v. m.

22. Salmo 49, II. Audi, popule meus, a 4 i 6 v. m. i orgue. Obra estrenada el 28 d'agost de 1961 en la vetllada d'homenatge a Mn. Aureli Querol, rector del Seminari.

23. Psalmus 150. Laudate Dominum in sanctis, a 4 v. m. i orgue.

24. Te Deum, a 4 i 6 v. m. i orgue. Partitura per a l'orgue (Mn. Ahís).

25. Credo de la Missa Jubilaris, a 6 v. m. i orgue.

26. Sanctus, Benedictus i Agnus de la Missa Jubilaris, a 6 v. m. i orgue.

27. Cuaderno de Música. Dirección. Amb la signatura de Mn. Vicent Garcia Julbe. De la Missa Jubilaris inclou:

Sanctus, a 6 v. m. i orgue.

Benedictus, a 3 v. m. i orgue.

Agnus, a 6 v. m. i orgue.

28. Missa Jubilaris, a 6 v. m. i orgue. Signatura de V. Garcia Julbe.

29. Assumpta est Maria, a 6 v. m.

30. Cantata In Dedicatione Ecclesiae, a 4 v. m., piano i orgue. Composta per a la Benedicció de l'església i Consagració de l'altar del Seminari Diocesà de l'Assumpció:

1) Cantate Domino. Cor.

2) Erexit Jacob lapidem.Domus mea. Coral.

3) Domine Deus, in simplicitate. Cor.

4) O quam metuendus est locus iste. Coral.

5) Domus mea. Recitatiu i Cor.

6) Laetatus sum. Final.

31. Cantata In Dedicatione Ecclesiae, a 4 v. m., piano i orgue. Partitura per al piano i l'orgue. ${ }^{8}$

8. Arxiu del Seminari Diocesà, Caixa 7. 
Altres obres de Mn. Vicent Garcia Julbe són:

32. Oh Jesús, perdona nuestras culpas, a 1 v. i orgue.

33. Magníficat, a 4 v. i. i orgue. Obra composta per a ser estrenada el dia 1 de novembre de 1950 , festa de Tots Sants, dia de la solemne proclamació dogmàtica del misteri de l'Assumpció de Nostra Senyora la Verge Maria, Mare de Déu. Còpia de l'original a l'Arxiu Pavia.

34. Missa in laudibus, a 4 v. i. i orgue. Còpia de l'original de 20 de juny de 1954 a l'Arxiu Pavia. 35. Astiterunt reges terrae, a 4 v. i. Adaptació del responsori homònim de T. L. de Victoria. Còpia a l'Arxiu Pavia.

36. Seniores populi, a 4. v. i. Adaptació del responsori homònim de T. L. de Victoria. Còpia a l'Arxiu Pavia.

37. Sepulto Domino, a 4 v. i. Adaptació del responsori homònim de T. L. de Victoria. Còpia a l'Arxiu Pavia.

38. Alleluia. Sollemnitas, a 4 v. m. Arxiu Coral Vicent Ripollés de Castelló.

39. Tradiderunt me, a 4 v. m. i solo. Arxiu Coral Vicent Ripollés de Castelló.

40. Salm 46. Omnes gentes, plaudite manibus, a 4 i 6 v. m. i orgue. Arxiu Coral Vicent Ripollés de Castelló.

41. Salm 150. Laudate Dominum in sanctis eius, a 4 v. m. i orgue. Arxiu Coral Vicent Ripollés de Castelló.

42. Dom Bueso, a 3 v. i. Harmonització de cançó popular. Còpia a l'Arxiu Pavia.

43. Molinera, a 3 v. i. Harmonització de cançó popular. Arxiu Coral Vicent Ripollés de Castelló.

44. Jo som es pastor més gros, a 3 v. i. Cançó nadalenca menorquina. Harmonització. Còpia de 16 d'abril de 1953 a l'Arxiu Pavia.

45. El calangrejo, a 3 v. i. Harmonització de cançó popular burgalesa. Còpia de 1953 a l'Arxiu Pavia.

46. Morito Pititón, a 3 v. i. Harmonització de cançó popular burgalesa. Còpia de 1953 a l'Arxiu Pavia.

47. A mi tots me diuen Toni, a 3 v. i. Cançó de batre. Harmonització. Còpia a l'Arxiu Pavia.

48. Tres hojitas, madre, a 3 v. i. Harmonització de cançó popular asturiana.

49. Os curas e taberneiros, a 3 v. i. Harmonització de cançó popular gallega.

50. Carmeleta, a 3 v. i. Sobre text de Bernat Artola. Arxiu Coral Vicent Ripollés de Castelló.

51. Cançó de Gener, a 3 v. i. Sobre text de Bernat Artola. ${ }^{9}$

52. Oremus pro Antistite, a 6 v. m. Estrenat en ocasió de les Noces d'Argent Episcopals del Bisbe Manuel Moll, el 7 de juny de 1962.

53. Hacia el glaciar, a 3 v. i. Harmonització de cançó popular d'Euskadi.

54. Tu es Sacerdos, a 4 v. m. i orgue. Cantata estrenada en ocasió de les Noces d'Argent Sacerdotals de Mn. Aureli Querol, el 28 d'agost de 1965.

55. Molinera, a 3 v. i. Harmonització de cançó popular asturiana.

56. Muntanyes regalades, a 3 v. i. Harmonització de cançó popular catalana.

57. Canto de pandeiro, a 3 v. i. Harmonització de cançó popular gallega.

58. Salm 29. Exhortación a acudir al templo, a 3 v. i. Obra estrenada el 28 d'agost de 1960 en la vetllada d'homenatge al rector del Seminari, Mn. Aureli Querol.

59. Salm 18. Himno latréutico a Dios creador y legislador, a 3 v. i. Obra estrenada el 28 d'agost de 1960 en la vetllada en homentage a Mn. Aureli Querol, rector del Seminari.

9. Informe Pavia 2001 i Arxiu Coral Vicent Ripollés de Castelló. 
60. Cuatro Cantigas del Rey Sabio. Harmonització a 3 i 4 v. i.

1. A cantar debemos.

2. Maravillosos et piadosos.

3. Se moito non amamos.

4. Todo logar mui ben.

61. Canto de pandeiro, a 3 i 4 v. Cançó popular gallega.

62. Molinero, a 3 i 4 v. Harmonització de cançó popular lleonesa.

63. Falade ben baixo, a 4 v. i. Harmonització de cançó popular gallega.

64. Lo desembre congelat, a 4. v. m. Harmonització de cançó popular catalana.

65. Caesarea Philippi. Cantata a 4 v. m., solo i orgue.

66. Alalá, a 4 v. i. Harmonització de cançó popular gallega.

67. Navideña, a 4 v. i. Harmonització de cançó popular gallega.

68. Alleluia, psallite, a 4 v. m.

69. Domine Deus, a 4 v. i.

El Seminari Diocesà era present de manera rellevant a totes les solemnitats litúrgiques de la Catedral, de la Diòcesi i del propi Seminari amb la participació de la Schola Cantorum dirigida per Mn. Vicent Garcia Julbe. Interpretàvem un amplíssim repertori musical que abraçava des de la música del Renaixement fins a la del segle XX passant pels segles XVII i XVIII, barrocs, i el XIX, romàntic. Ens eren familiars els clàssics Francisco Guerrero, Joan Baptista Comes, Ginés Pérez, Mateu Fletxa el Vell, Tomás Luis de Victoria, Giovanni Pierluigi da Palestrina, Claudio Monteverdi, Johan Sebastian Bach, W. A. Mozart, J. F. Haydn, G. F. Händel, Antonio Vivaldi, Grieg, Chopin, Liszt, Wagner, Fèlix Mendelssohn, J. Brahms, F. Schubert, Ch. Gounod, Felip Pedrell, Albéniz, Granados, Manuel de Falla, Josep Ma Peris, Vicent Ripollés, Otaño, V. Goicoechea, V. Garcia Julbe, V. Göller, A. Lotti, G. Ett, Ernesto Halffter i d'altres. I complementàvem el repertori clàssic amb un abundant repertori de cançons populars catalanes, mallorquines i menorquines, valencianes i castellanes harmonitzades per diversos mestres, sobretot pels mestres Pedrell, Ripollés, Peris, Garcia Julbe, Millet, Cumellas Ribó i Lamote de Grignon.

La Schola Cantorum del Seminari era un microcosmos presidit per un excel-lent demiurg, Mn. Vicent Garcia, que cuidava de l'originalitat creativa, composició, direcció, distribució de les funcions i preparació del personal més adequat per a exercir-les -organistes, copistes, responsables de l'Arxiu Musical, pianistes, solistes, responsables de les cordes, responsables dels assaigs-. Les diverses agrupacions de veus, provades a cada alumne des del primer dia que entràvem al Seminari, eren dividides en tiples primers, tiples segons o contralts, tenors primers, barítons i baixos. Dedicàvem molt de temps a assajar les obres noves i a repasar les antigues per tal de no minvar i perdre repertori. Cada any, en tornar de les vacances de Nadal iniciàvem els assajos de tot el repertori que havíem de cantar per Setmana Santa a les solemníssimes funcions litúrgiques de la Catedral. Sempre hi solia haver alguna obra nova composta pel nostre estimat director i mestre que s'afegia al repertori de Victoria, Ginés Pérez, Otaño, Lotti, Ett, Goicoechea i Tàpies. 
Mn. Vicent Garcia comptava amb directors auxiliars que ajudaven a preparar les diferents veus tot solfejant per separat les partitures abans de conjuntar-se les veus sota la seva direcció. Recordem alguns d'aquests directors auxiliars: Lino Vives i Garcia, el darrer any que el Seminari Major era al Col-legi de Sant Josep, Santiago Vilanova i Verdià, Ignasi Pérez de Heredia i Valle, Pasqual Notari i Pitarch, Josep Pavia i Simó, Carles Castillo i Meseguer, Artemi Fabregat i Deusdad, Vito Climent i Gasulla, Antoni Melià i Fortuna, Joaquim Segura i Giner, Rossend Aymí i Escolà, Josep Alanyà i Roig, Isaïes Riba i Cucala, ja en el nou Seminari. En algunes ocasions dirigien també la Schola en absència del director.

Molt especialment i en un altre nivell fou un ajut i col-laborador permanent de Mn. Garcia Julbe el professor de música i compositor Mn. Jaume Sirisi i Escoda, qui havia dirigit la Schola Cantorum fins que arribà a Tortosa Mn. Vicent Garcia i l'havia preparat amb tanta exigència i perfecció que el nou Canonge Prefecte de Música Sagrada no hagué de fer altra cosa sinó potenciar-la fins al brillant nivell que assolí sota la seva batuta.

La Schola reproduïa en ciclostil de gelatina les partitures de les diferents veus en el que avui diríem autoedició i també en còpies manuscrites, quan calia, partitures que es guardaven a l'Arxiu Musical en carpetes ordenades juntament amb les partitures de direcció, les unes impreses i les altres manuscrites, i totes les partitures de les obres de Mn. Vicent Garcia Julbe, originals. Ja he dit que aquestes partitures de l'estimat mestre eren sempre escrites en llapis i hi havia membres de la Schola que s'encarregaven de passar-les a tinta perquè no s'esborressin i perdessin. Generalment, per tal que la tasca no resultés feixuga, un escrivia la lletra i un altre les notacions dels pentagrames.

Per tal d'estar al dia del repertori musical la Schola Cantorum del Seminari estava suscrita a l'ESSET de Vitòria, d'on ens arribaven partitures i cants nous. D'aquí ens arribà el cant «Cerca de tí, Señor», a veus, que la Schola interpretà per primer cop al Seminari el curs 1953-54 i des d'on es difongué per tota la Diòcesi tortosina. Del contacte de la Schola amb el País Basc se'n responsabilitzava Mn. Ignasi Pérez de Heredia i Valle per la facilitat que tenia de fer-ho en passar els estius allí.

Un grup propi en l'àmbit musical del Seminari el constituïen els organistes, que inicialment tocaven un antic harmònium, de bona factura i sonoritat, de la casa H. Christofle \& Etienne, que Mn. Garcia Julbe estimava i sempre havia preferit als nous orgues electrònics. Recordem els següents:

Mn. Constantino Ahís i Escrig, Mn. Joan Ramon Herrero i Llidó, Mn. Jesús Reboll i Maneu, Mn. Manuel Jordà i Estupiñà, Mn. Rossend Aymí i Escolà, Mn. Isaïes Riba i Cucala, Mn. Josep Fontanet i Vives, Josep Cutrona i Domènech, Josep Roda i Batlle, Mn. Rafel Prades i Antolí, Mn. Víctor Manuel Cardona i Eixarch, Joan Josep Ribes i Curto i Enric Polo i Moya.

L'harmònium del Seminari fou adquirit, a instàncies del bisbe Manuel Moll, de la parròquia d'Orpesa, l'any 1947, gràcies a les gestions de Mn. Lluís Arrufat (1872-1947), beneficiat de l'Arxipresal de Santa Maria de Castelló. Era un harmònium de la fàbrica d'harmòniums per a capelles i salons de la Casa francesa «H. Christofle et Etienne», del carrer de Charonne, 97, a París, que tenia el mostrari a Barcelona, al carrer Aribau 9, pral. 2 ${ }^{\mathrm{a}}$, i el seu responsable era Geor- 
ges Crochet. La casa constructora de l'harmònium havia aconseguit Medalla de Bronze a l'Exposició Universal de París de 1867, Medalla d'Argent el 1878 i, darrer premi, la Medalla d'Or, el 1889. Aquest harmònium, que és una autèntica peça arqueològica de gran valor, és encara en servei a l'oratori de la cripta de l'església del Seminari. És un harmònium d'un sol teclat transpositor, de 8 jocs, 19 registres i 5 octaves. Corn anglès, Bordó, Sordina, Arpa Eoliana, Fagot, Fort, Còpula, Expressió, Joc gran al genoll, Genolleres de Forte, Flauta, Clarinet, Veu Celesta, Trèmolo, Oboè, Dolçaina, Veu Celesta, Fort i Còpula. Moble en fusta de roure i teclat transpositor. Les seves mides: $120 \mathrm{~cm}$ d'alt, $143 \mathrm{~cm}$ d'ample, $80 \mathrm{~cm}$ de profunditat. Pes: $190 \mathrm{~kg}$. El cost en francs d'un harmònium com aquest, a les darreries del segle XIX, que és quan s'adquirí, era de 3.000 francs. $^{10}$

Aquest harmònium fou desplaçat del cor de l'església del Seminari quan fou adquirit a Sant Sebastià un orgue electrònic «Harmoniphon», de tres teclats manuals i pedal, a recomanació de Mn. Francesc Tàpies, Canonge Organista de la Catedral de Tarragona, l'any 1958. Aquest orgue, que figura regalat, fou estrenat a la Catedral en el solemne funeral pel Papa Pius XII i, un cop pujat al Seminari, amb un concert del canonge Tàpies el dia 1 de febrer del mateix any. Poc després, el mateix any, s'instal·là un altre orgue electrònic «Harmoniphon» a la Catedral, que és el que hi sona encara actualment. ${ }^{11}$ El bisbe Moll en donava la descripció per boca de D. Jenaro a «Surco»: «Es un magnífico instrumento de tres teclados manuales, de treinta y ocho registros completos, pedalero de treinta y dos notas y cuatro pedales de expresión... Es precisamente el órgano que han regalado al Seminario... Un órgano tubular con todos estos detalles dichos, se acercaría al millón de pesetas... Además, dentro de los órganos electrostáticos, hay modelos muy estimables, de precios inferiores al del nuestro, acomodados a las posibilidades de las iglesias aun modestas.» I defensava, contra els detractors dels orgues electrònics, llur bondat: «Nadie discute que el órgano tubular es el órgano por antonomasia, clásico, tradicional, el instrumento litúrgico por excelencia. En esto hay conformidad absolutísima. Más aún, si nuestras iglesias hubieran conservado, empezando por nuestra Catedral, aquellos órganos tubulares magníficos que tenían, construidos a conciencia, con materiales selectísimos, a nadie se le ocurriría, si no fuese un loco, eliminar aquellos órganos y reemplazarlos por otros electrostáticos... Y la realidad nos dice... que la adquisición de órganos tubulares buenos y de categoría, hoy por hoy está reservada a contadas iglesias... Por la sencilla razón de que el precio de un tal órgano tubular es de un millón de pesetas para arriba... Y si lo quiere Ud. de categoría alta, prepare dos, tres y más millones.» ${ }^{12}$

Les actuacions litúrgiques de la Schola eren a l'església del Seminari, a la Catedral, a les esglésies dels convents en celebracions solemnes i en algunes de les esglésies que s'inauguraren durant el pontificat del bisbe Moll: Camarles, Amposta, Móra d'Ebre, Xert... Les actuacions profanes les teníem generalment al saló d'actes del Seminari en les vetllades musicals, on cantàvem música religiosa i profana, tant clàssica com popular.

10. Arxiu Josep Audenis. Barcelona, Precios corrientes de la acreditada Fábrica de Armoniums para Capillas y Salones $H$. Christofle y Etienne, rue de Charonne, París.

11. Surco, febrer de 1959, p. 2.

12. Surco, novembre de 1958 , p. 3. 
L'any 1949 la Schola coronà els cants de la Setmana Santa a la Seu tortosina amb la interpretació del Miserere a 6 v. m. de V. Goicoechea, sota la direcció de Mn. Jaume Sirisi i Escoda. ${ }^{13}$

A principi del curs 1949-50 s'incorporà al Seminari com a professor de Teologia i Música i director de la Schola Cantorum el M. Iltre. Mn. Vicent Garcia Julbe, nomenat Canonge Prefecte de Música Sacra de la Catedral tortosina. Amb la seva arribada es reactivà la vida de la Schola amb el treball conjunt i a fons, molt ben coordinat de Mn. Garcia Julbe i Mn. Josep Sirisi, el seu fidel col-laborador. «Surco» en donava fe: «La intensa vida musical de ambos Seminarios ha recibido un nuevo y particular impulso bajo la batuta del insigne maestro M. I. Sr. D. Vicente García Julbe, Canónigo Prefecto de Música de la S. I. Catedral B. Las melodías clásicas de la «Missa Quarti Toni», de Victoria, en la Fiesta del Colegio, los ensayos frecuentes y depurados en ambos Seminarios, las clases de piano y, sobre todo, las de harmonía, dan fe evidente de lo dicho.» ${ }^{14}$

L'any 1950, per a la festa de Sant Tomàs, la Schola estrenà la «Missa in laudibus», a 4 v. i. i orgue, de Mn. Vicent Garcia. I per la Setmana Santa es cantà el repertori brillant de tants d'anys, amb els responsoris de T. L. de Victoria i d'Otaño, el «Miserere» de Goicoechea, el «Benedictus» de Ginés Pérez i la «Missa in laudibus» de Vicent Garcia el dia de Pasqua.

El dia 1 de novembre de 1950 el Papa Pius XII declarava solemnement Dogma de Fe l'Assumpció de la Verge Maria en cos i ànima al cel, misteri de la vida de Santa Maria que esdevingué titular del Seminari Diocesà. Aquell mateix dia, a les segones Vespres de la festa la Schola estrenà el «Magnificat», a 4 v. i. i orgue de Mn. Vicent Garcia, obra composta a honor de l'Assumpció de Maria. ${ }^{15}$

La Semana Santa de 1951 començà a cristal·litzar el repertori litúrgic dels oficis i misses de la Semana Major amb els cants de T. L. de Victoria, J. B. Comes, V. Garcia Julbe, Otaño, V. Goicoechea, A. Lotti, etc. «Surco» parlà ja aleshores del «éxito musical -y que estos términos no profanen la santidad de aquellos días- que obtuvo el Seminario cantando en la Catedral los días santos, lo que empieza a constituir una tradición y un acontecimiento. Nunca había rayado a tanta altura la interpretación de Victoria, Comes, Goicoechea, García, etc. Nunca los fieles se habían manifestado tan fieles y asiduos. Nunca fue más justa y halagadora la fervorosa felicitación que el Seminario recibió por ello del Reverendísimo Prelado.» ${ }^{16}$ En la Setmana Santa de 1953 la Schola cantà íntegre l'Ofici de la Setmana Santa de Tomás Luis de Victoria i edità un díptic o programa de mà amb les diferents actuacions a la Catedral i les obres interpretades, que s'obria amb aquesta nota invitatòria: «Las sagradas evocaciones de la Semana Santa litúrgica se expresan abundantemente en un lenguaje musical, el más conmovedor y bello. Nuestro Seminario Diocesano de la Asunción lo hará resonar bajo las bóvedas de la Seo. Unas veces el severo canto gregoriano de los salmos y las antífonas y otras la polifonía sagrada clásica y moderna, extranjera y española: Palestrina, Lasso, Comes, Ginés Pérez, Ett, Göller, Réfice, Otaño, García Julbe. Sobre todo la obra entera del gran T. L. de Victoria. Y la maravilla moderna del Miserere de V. Goicoechea.»

13. Surco, maig de 1949 , p. 2.

14. Surco, desembre de 1949, p. 2.

15. Surco, desembre de 1950, p. 2.

16. Surco, abril de 1951 . 
La Schola Cantorum, mentre existí, solemnitzà a gran nivell musical la Setmana Santa de la Catedral de Tortosa. Començàvem la participació litúrgica el matí del Diumenge de Rams en la benedicció de les palmes, la processó i la missa solemne.

A. Diumenge de Rams

1. Processó: Cantàvem les antífones «Occurrunt», «Cum angelis», «Turba multa» $\mathrm{i}$ «Ingrediente» en cant gregorià, el «Pueri hebraeorum», a 4 v. i., de G. P. de Palestrina, i l'himne «Gloria, laus», a 4 v. m., de V. Garcia Julbe.

2. Missa: Parts variables en gregorià. Les parts invariables eren polifòniques i en diversos anys cantàvem les misses de diferents compositors clàssics. Havíem cantat aquestes misses:

1. Missa «Quarti toni», a 4 v. m., de T. L. de Victoria.

2. Missa a 3 v. i. d'A. Lotti.

3. Missa a 4 v. i., de M. Asola.

Credo:

1. Gregorià.

2. Credo a 4 v. i. de Palestrina-Pagella.

Passio D. N. Iesu Christi secundum Matthaeum, a 4 v. m., de G. Ett.

A la nit la Schola participàvem en la Processó de la Passió pels carrers de Tortosa.

B. Dimecres Sant. Maitines i Laudes. Ofici de Tenebres. A la tarda.

1. Matines. Antífones i salms: Cant Gregorià.

Lamentacions de Jeremies: Cant Gregorià.

Responsoris:

I. In monte Oliveti, a 4 v. i., de N. Otaño.

II.Tristis est, a 4. v. i., de N. Otaño.

III.Ecce vidimus, a 4 v. i., de N. Otaño.

IV.Amicus meus, a 4 v. m., de T. L. de Victoria.

V. Judas mercator, a 4. v. i., de T. L. de Victoria.

VI. Unus ex discipulis, a 4 v. m., de T. L. de Victoria.

VII. Eram quasi agnus, a 4. v. m., de T. L. de Victoria.

VIII. Una hora, a 4 v. i., de T. L. de Victoria.

IX. Seniores populi, a 4 v. m., de T. L. de Victoria.

2. Laudes. Antífones i salms: Cant Gregorià.

Càntic del «Benedictus», a 4 v. m., de Ginés Pérez.

Antífona «Christus factus est», a 5 v. m., de V. Goicoechea.

Antífona «Christus factus est», a 4 v. m., de J. B. Comes.

Salm «Miserere», a 4 i 6 v. m., de V. Goicoechea.

C. Dijous Sant.

1. Missa Crismal. Al matí.

Parts variables: Cant Gregorià.

Havíem cantat aquestes misses:

1. «Missa Festiva», a 3 v. m. i orgue, de L. Réfice.

2. «Missa Festiva», a 3. v. i. i orgue, de Mitterer.

3. «Missa Brevis», a 3 v. i. i orgue, de A. Montani.

4. Missa «Salve Regina», a 4 v. i. i orgue, de J. G. E. Stehle. 
5. Missa «Quarti toni», a 4 v. m., de T. L. de Victoria.

2. Missa in Cena Domini. A la tarda.

Parts variables: Cant Gregorià.

Havíem cantat les misses següents:

1. «Missa Festiva», a 3. v. m. i orgue, de L. Réfice.

2. Missa «Gratia Plena», a 3 v. m., de L. Réfice.

3. «Missa Choralis», a 3 v. i., de L. Réfice.

4. Missa «O quam gloriosum», a 4 v. m., de T. L. de Victoria.

5. «Missa Jubilaris», a 6 v. m. i orgue, de V. Garcia Julbe.

Rentat dels peus. Antífones: Cant Gregorià.

Ofertori: «Dextera Domini», a 4 v. i., de V. Garcia Julbe.

Comunió:

1. «Domine, non sum dignus», a 4 v. i., de T. L. de Victoria.

2. «Miserere mei quoniam», a 4 v. i., de T. L. de Victoria.

3. «Verbum caro», a 3 v. m. d'O. de Lasso.

Processó:

1. «Pange lingua», a 4 v. m., de G. P. de Palestrina.

2. «Tantum ergo», a 4 v. i., de V. Garcia Julbe.

D. Divendres Sant.

Ofici de Tenebres. Matines i Laudes. Al matí.

1. Matines. Antífones i salms: Cant Gregorià.

Lamentacions de Jeremies: Cant Gregorià.

Responsoris:

I. Omnes amici, a 4 v. i., de N. Otaño.

II. Velum templi, a 4 v. i., de N. Otaño.

III.Vinea mea, a 4 v. i., de N. Otaño.

IV. Tamquam ad latronem, a 4 v. m., de T. L. de Victoria.

V. Tenebrae factae sunt, a 4 v. i., de T. L. de Victoria.

VI. Animam meam dilectam, a 4 v. m., de T. L. de Victoria.

VII. Tradiderunt me, a 4 v. m., de T. L. de Victoria.

VIII. Jesum tradidit, a 4 v. i., de T. L. de Victoria.

IX. Caligaverunt, a 4 v. m., de T. L. de Victoria.

2. Laudes. Antífones i salms: Cant Gregorià.

Càntic del «Benedictus», a 4 v. m., de Ginés Pérez.

Antífona «Christus factus est», a 5 v. m., de V. Goicoechea.

Antífona «Christus factus est», a 4 v. m., de J. B. Comes.

Salm «Miserere», a 4 i 6 v. m., de V. Goicoechea.

Salm «Miserere», a 4 v. i., de V. Garcia Julbe.

3. «Missa Praesanctificatorum» (abans de la reforma de la Setmana Santa). Al matí. Post reforma: Ofici «In Passione et Morte Domini». A la tarda.

Responsoris «Domine» $i$ «Eripe me»: Cant Gregorià.

«Passio D. N. Iesu Christi secundum Joannem», a 4 v. m., de T. L. de Victoria.

Improperis «Popule meus», a 4 v. m., de T. L. de Victoria.

«Adoramus te», a 4 v. m., de G. P. de Palestrina.

Himne «Vexilla Regis», a 4 v. i., de L. Refice. 
«O Crux», a 4 v. m., de Ginés Pérez.

A la nit la Schola cantàvem a la Processó del Sant Enterrament pels carrers de Tortosa.

E. Dissabte Sant. Ofici de Tenebres. Matines i Laudes. Al matí.

1. Matines. Antífones i salms: Cant Gregorià.

Lamentacions de Jeremies: Cant Gregorià.

Responsoris:

I. Sicut ovis, a 4 v. i., de N. Otaño.

II. Jerusalem, surge, a4 v. i., de N. Otaño.

III. Plange quasi virgo, a 4 v. i., de N. Otaño.

IV. Recessit Pastor, a 4 v. m., de T. L. de Victoria.

V. O vos omnes, a 4 v. i., de T. L. de Victoria.

VI. Ecce quomodo moritur, a 4 v. m., de T. L. de Victoria.

VII.Astiterunt, a 4. v. m., de T. L. de Victoria.

VIII. Aestimatus sum, a 4 v. i., de T. L. de Victoria.

IX. Sepulto Domino, a 4 v. m., de T. L. de Victoria.

2. Laudes. Antífones i salms: Cant Gregorià.

Càntic del «Benedictus», a 4 v. m., de Ginés Pérez.

Antífona «Christus factus est», a 4 v. i., de G. P. de Palestrina.

Després de la reforma litúrgica de la Setmana Santa, un grup de la Schola Cantorum baixàvem a la nit a la Catedral per fer-nos càrrec de la part musical de la Vetlla Pasqual.

F. Diumenge de Pasqua de Resurrecció.

Missa Pontifical. Al matí.

Parts variables: Cant Gregorià.

Sequiència «Victimae paschali»: Cant Gregorià.

Havíem cantat les misses seguients:

1. «Missa secunda», a 4 v. m. i orgue, de V. Goller.

2. «Missa Brevis», a 4 v. m. i orgue, de V. Goller.

3. «Missa Jubilaris», a 6 v. m. i orgue, de V. Garcia Julbe.

4. Missa «O quam gloriosum», a 4 v. m., de T. L. de Victoria.

Credo de la «Missa del Papa Marcelo», a 6 v. m., de G. P. de Palestrina.

Credo de la Missa «O quam gloriosum», a 4 v. m., de T. L. de Victoria.

Ofertori: «Alleluia, psallite», a 4 v. m., de V. Garcia Julbe.

«Regina caeli», a 4 v. m., d'A. Lotti. ${ }^{17}$

La Schola Cantorum interpretàvem obres de l'Edat Mitjana, del Renaixement i del Barroc espanyols, algunes de les quals havien estat descobertes i transcrites pel nostre mestre i director, Mn. Vicent Garcia Julbe, als arxius musicals del Patriarca, de la Catedral de Sant Jaume de Galícia i de la pròpia Seu de Tortosa. Són dignes d'esmentar aquestes:

1. Ave Maria, a 8 v. m., de T. L. de Victoria.

17. Programes de mà de la Setmana Santa a la S.I.C.B. de Tortosa. Informe Riba 2001. 
2. Haec dies est sancta. Himne gregorià del segle XIII. Còdex 145 de l'Arxiu Capitular de Tortosa.

3. Apuestan zagales dos. Villanesca, a 5 v. m., de Francisco Guerrero, segle XVI.

4. Pastor, quien Virgen Madre. Villanesca, a 3 v. i., de F. Guerrero, segle XVI.

5. Para regalo y bien mío. Villancico, a 4 v. i., de J. B. Comes. València, segle XVII.

6. Sanctus in honorem B. M. Virginis. Melodia gregoriana amb trops. Catedral de Tortosa, segle XI. Còdex 135 de l'Arxiu Capitular.

7. A creer debemos. Cantiga del rei Alfons el Savi. Còdex de l'Escorial, segle XIII.

8. Todo logar moi ben. Cantiga del rei Alfons el Savi. Còdex de l'Escorial, segleXIII.

9. Vidi speciosam. Motet a 6 v. m., de T. L. de Victoria.

10. Esclarecida Madre. Villanesca, a 4 v. i., de F. Guerrero, segle XVI.

11. Dulcísima María. Villanesca, a 4 v. i., de F. Guerrero, segle XVI.

12. A la Inmaculada Concepción. Cantata a 3 cors i 12 v. m., de Joan Baptista Comes. Segle XVII.

13. In Assumptione B. M. V., a 6 v. m., de T. L. de Victoria. Pars prima: Vidi speciosam ascendentem. Pars secunda: Quae est ista quae ascendit.

14. La Pàtria nova (Landerkennung), a 4 v. m., de Grieg.

15. Ave Maria, a 4 v. m. i orgue, de V. Goller.

16. Tantum ergo, a 3 v. m. i orgue de L. Iruarrízaga.

17. Tantum ergo, a 3 v. i., de Hamma.

18. Sancta et Immaculata, a 4 v. i., de F. Guerrero. S. XVI.

19. Alabada sea, a 4 v. i., de J. B. Comes. S. XVI.

20. El Misteri d'Elx. La Vesprà. Dormició de Maria. La Festa. Enterrament i Coronació.

21. Ave Maria, a 4 v. i., de V. Goicoechea.

22. Tres villanescas de F. Guerrero, a 3 i 4 v. i., de l'Opera omnia, vol. II. Transcripció de V. Garcia Julbe.

23. Tres villancicos del Cancionero del siglo XVII, a 3 v. Biblioteca Nacional de Madrid.

24. Cantata escènica «L'Atlàntida», de Manuel de Falla-Ernesto Halffter.

$3^{\mathrm{a}}$ part:

A) De «El somni d'Isabel»:

a) Christophorus: haec dixit Dominus...

b) Colom ab sos companys....

B) De «Les Caravelles»:

a) Piano.

b) Qui sunt isti.

c) De cara al sol que es pon.

d) La Salve en el mar...

25. Danzas del Santísimo Corpus Christi, a 4 i 8 v. m., de J. B. Comes, segle XVI.

26. Música jacobea de l'Arxiu de la Catedral de Sant Jaume de Galícia:

1. Clarines de zafir, a 4 v. i., de J. Vaquedano, segle. XVII.

2. Al armonía de trompeta, a 8 v. i., de J. Vaquedano.

27. Música medieval de la Seu de Tortosa. Còdex 135 de la Biblioteca Capitular. Segles XIIIXIV. Transcripció de V. Garcia Julbe.

1. In honorem Sancti Laurentii.

2. In honorem Sancti Augustini.

3. In Assumptione B. M. V. 
28. Cantata a Ntra. Sra. de la Cinta, a 4 i 8 v. i acompanyament, de Mn. Josep Escorihuela, Mestre de Capella de la Seu. Any 1723. Arxiu Capitular de la Seu de Tortosa.

29. Cantata a Ntra. Sra. de la Cinta: Ah de la centinela, a 2 cors i 8 v., de Mn. Josep Escorihuela. Any 1724. Arxiu Capitular de la Seu de Tortosa.

30. Villancico a San Agustín, a 4 v. i acompanyament, de Mn. Josep Escorihuela. Any 1719. Arxiu Capitular de la Seu de Tortosa.

31. Himno a San Agustín. Himnari del segle XIII. Còdex 135 de l'Arxiu Capitular de Tortosa.

32. Himno a San Lorenzo. Himnari del segle XIII. Ibidem.

33. Villancico al apóstol Santiago, a 8 v. m. i acompanyament, de F. Vaquedano. S. XVII. Arxiu de la Seu de Sant Jaume de Galícia. Transcripció de V. Garcia Julbe.

34. Carmina philosophorum:

I. Sapientia.

II. Cum tentamina.

III. Juvenes.

IV. Gloriemur.

35. Madrigalistes clàssics:

1er. quartet. "Adiós verde ribera», de F. Guerrero.

2n. quartet. «Prado ameno», de F. Guerrero.

Quartet doble. «Esclarecida madre», de F. Guerrero.

36. Romances y letras a tres voces. Cancionero del siglo XVII. Biblioteca Nacional de Madrid.

1. En Belén están mis amores. Villancico.

2. Soberana María. Villancico.

3. Válame Dios. Villancico.

4. Por la puerta. Romance.

5. Vivo yo, mas no yo. Letra.

6. Los rayos del sol impiden. Letra.

37. Oh luz de nuestras almas, a 6 v. m. i orgue, de I. Busca de Sagastizábal.

38. Cor de pelegrins, a 4 v. i, de l'òpera «Tannhäuser», de R. Wagner.

39. A cantar debemos. Cantiga del rei Alfons el Savi. Harmonització a 3 i 4 v. i. de V. Garcia Julbe.

40. Maravillosos e piadosos. Cantiga del rei Alfons el Savi. Harmonització a 3 i 4 v. i. de V. Garcia Julbe.

41. Se moito non amamos. Cantiga del rei Alfons el Savi. Harmonització a 3 i 4 v. i. de V. Garcia Julbe.

42. Todo logar mui ben. Cantiga del rei Alfons el Savi. Harmonització a 3 i 4 v. i. de V. Garcia Julbe.

El complement musical de les actuacions de la Schola Cantorum eren els diversos recitals de piano que donaven els alumnes del Seminari exhibint els progressos que feien en la pràctica i mètode d'aquest instrument. Recordem les magnífiques interpretacions d'alguns alumnes de piano molt ben dotats i que després han estat mestres en l'art musical com ara Rossend Aymí i Escolà i Joan Ramon Herrero i Llidó o Avel·lí Flors, organistes, compositors i directors de cor. Però molts d'altres també mostraven les habilitats pianístiques en les vetllades de la Immacula- 
da Assumpta i de Sant Aureli Agustí. Dels intèrprets i de la música escollida en pot ser, aquesta que segueix, una bona mostra:

1. Rossend Aymí i Escolà:

Manuel de Falla, «El Sombrero de tres picos»: Danza del Molinero. «El amor brujo»:

Danza del Fuego.

2. Rossend Aymí - Antoni Melià:

L. van Beethoven, $5^{a}$ Simfonia en do menor, 1r. temps.

3. Badenes - Fontanet:

Diabelli, Estudis $6 \grave{e} i$ 8è. Melodies.

4. Flors - Martínez:

Fritz Spindler, Sonates $1^{a} i 2^{a}$.

5. Aymí - Segura:

P. Mascagni, Intermezzo de "Cavalleria rusticana».

A. Diabelli, Polonesa.

6. Jordà - Castillo:

Cèsar Franck, Preludi, fuga i variació (piano i harmònium).

7. M. Gil - I. Riba:

M. Bosch, Marxa.

8. A. Blas - I. Riba:

M. Bosch, Meditació.

9. J. Fontanet - I. Riba:

A. Diabelli, Sonatina.

10. M. Royo - F. Agut:

R. Schwalm, Melodia.

11. J. Monferrer - F. Agut:

A, Diabelli, Cançó.

12. J. Rebull - F. Agut:

Ch. Schumann, Ària.

13. F. Civit - F. Agut:

Ch. Schumann, Del Pilar al Cielo.

14. A. Flors - R. Aymí:

Haydn, Menuett de la Simfonia en Re major.

15. R. Vaquer - E. Sales:

W. A. Mozart, Ària de Fígaro.

16. F. Civit - A. Fabregat:

W. A. Mozart, Al-leluia (Cant i piano).

17. F. Agut - I. Riba:

Diabelli, Sonatina, Opus 163.

18. R. Aymí - A. Flors:

Ludwig van Beethoven, Andante de la $5^{a}$ Simfonia. (Reducció per a piano a quatre mans).

19. F. Civit - M. Gil:

J. B. Duvernoy, Nàpols i Florència (Fantasia).

20. J. Gil - H. Sans:

R. Schumann, Le jour de fête (Marxa).

21. R. Aymí - A. Melià: 
Ludwig van Beethoven, Simfonia en Do menor, $V$. (Reducció a piano).

22. J. Roda - A. Bru:

R. Chapí, Coro de doctores de "El rey que rabió».

23. J. E. Peris:

E. Granados, Danzas españolas, núm. II.

24. M. Gil:

E. Granados, Danzas españolas, núm. IV.

25. J. Cutrona:

E. Granados, Danzas españolas, núm. VI.

27. I. Riba:

E. Granados, Danzas españolas, núm. III.

28. Rossend Aymí:

S. Rachmaninoff, Preludi en Do sostingut menor.

29. J. Roda:

Sonates de Beethoven. Opus 26, Allegreto final.

30. J. Cutrona:

Sonates de Beethoven, Opus 13, I temps.

31. Isaïes Riba:

Sonates de Beethoven, Opus 31, núm. 1, Allegro vivace, I temps.

32. Rossend Aymí:

Sonates de Beethoven, Opus 27, núm. 2, Presto Agitato Final.

33. Rafel Prades:

M. Clementi, Opus 36 en Do major, Allegro, Andante, Vivace.

34. Ramon Font, Antoni Bordás i J. Vidal:

Steibelt, En Do major. Andantino (R. Font), Moderato (A. Bordás), Allegro (J. Vidal).

35. J. Ribes:

Steibelt, Opus 36, núm. 2, Allegro final.

37. Rafel Prades:

F. Schubert, Serenata.

J. Strauss, «Danubio Azul».

38. J. J. Ribes:

L. van Beethoven, «Para Elisa».

J. Ivanovici, «Olas del Danubio».

Hi hagué, però, al Seminari Diocesà un pianista excepcional que venia de Vinaròs, en la seva adolescència, a donar-nos uns concerts de piano que eren una meravella. Aquest jovenet era Carles Santos i Ventura, pianista i compositor, qui als seus catorze anys, el 18 de gener de l'any 1953, pujava al Seminari de la mà de Mn. Vicent Garcia Julbe, el seu professor, qui ens el presentà, per oferir un brillant concert davant tota la comunitat presidida pel bisbe Moll, «un maravilloso concierto de piano, de música clásica»: «aquella inolvidable lección que Carlos Santos les dictó desde el teclado con su arte y con su sencillez a los alumnos del Seminario, que desde entonces lo consideran como un amigo más a quien admiran y quieren», com escrivia Mn. Aureli Querol, rector de la casa, a la secció «Aquí, Seminario» de «Surco». El rector del Seminari el felicitava per l'actuació i li augurava el millor futur en el camp musical, «el augurio y la seguridad de 
que triunfará plenamente en el terreno del Arte; y el orgullo de haber sido el Seminario de Tortosa quien haya recibido las primicias de su prodigiosa madurez para conciertos». ${ }^{18}$

Carles Santos tornà al Seminari per regalar-nos amb nous concerts. Ho féu el dia 12 d'octubre de 1953, «artista consumado a sus trece años», «para obsequiar al Seminario con el regalo de su arte exquisito, de su ejemplar entrega a una vocación y de su sencillez atractiva que le hace sentirse entre los niños y los jóvenes del Seminario como un compañero más.» Afegia Mn. Querol: «No sabe él -¡vamos, sí lo sabe!- cuánto se le quiere y se le agradece en el Seminario de Tortosa su amabilidad. Presidió el concierto el Rvdmo. Prelado. El programa, todo él clásico y selecto. Los progresos de Carlos, innegables. Nos complació que se haya restablecido tan perfectamente de su rotura de muñeca. El voto general de los buenos amigos de Carlos en el Seminario de Tortosa, que son todos los Superiores y alumnos, es para que Carlos Santos triunfe plenamente en el mundo del Arte para el que está llamado. ¡Y muchas gracias, Carlos! A tí y a tus buenos y complacientes padres.» ${ }^{19} \mathrm{El}$ jove pianista rebia aquest any la felicitació del Seminari per haver triomfat amb Premi Extraordinari al Conservatori del Liceu. I el felicità més tard, l'any 1960, pels seus èxits com a famós concertista de piano, «un modo de demostrarle que no olvidamos sus repetidas bondades con el Seminario y que su primer concierto público lo dio en el Seminario». ${ }^{20}$

Aquells inicis musicals, exhibits al Seminari de Tortosa els anys 1953, 1954 i 1955, eren auguri de la fama artística d'intèrpret i compositor del músic de Vinaròs, qui, el 1959, tornaria al Seminari per assajar els Goigs a Sant Sebastià que compongué i nosaltres, vull dir la Schola Cantorum, estrenàrem per a les solemnes festes del Cinquantenari de la Relíquia de Sant Sebastià. Al seu torn, Mn. Vicent Garcia Julbe havia compost la «Missa Jubilaris», a 6 v. m. i orgue, que estrenàrem en la festa del Reservat de 1959 i cantàrem a Vinaròs, amb els Goigs de C. Santos, en la missa pontifical del Cinquantenari.

Carles Santos, alumne del Conservatori del Liceu, amplià estudis amb J. Février i Magda Tagliaferro. És director artístic, juntament amb J. M. Mestres i Quadreny, del Grup Instrumental Català (1977). S'ha especialitzat en la interpretació de música contemporània i ha obert camins innovadors de gran originalitat en aquest camp al nostre país i al món sencer. És autor d'accions musicals, amb música, llibret, interpretació i direcció escènica seves, com Homenatge a Joan Brossa, Concert irregular i ha estat director musical de les representacions de Mahagonny. És també autor de diversos espectacles musicals, on intervenen cantants d'òpera, mims, artistes de circ funàmbuls i malabaristes, que ha representat a Espanya i a l'estranger, de la seva darrera òpera, «Ricardo y Elena» i d'una versió pròpia de «El barbero de Sevilla», de Rossini, estrenada recentment al Festival de Peralada. Ha participat en el Festival d'Edimburg, en el de La Villette de París, en el Teatre Nacional de Catalunya i en l'Auditori de València, a més de molts altres llocs de les més grans i cultes ciutats del món. L’obra més recent, estrenada a l'Auditori de València el febrer del 2001, ha estat la gran cantata intitulada «L'adéu a Lucrècia Borja» sobre la vida de la

18. Surco, febrer de 1953, pp. 2 i 4.

19. Surco, novembre de 1953, p. 2.

20. Surco, juny de 1960, p. 2. 
família dels Borja, amb text de Joan Francesc Mira, una cantata de grans proporcions, de llarga durada -cinc quarts sense descans-, en la qual participen quasi 200 intèrprets, això és, un gran cor, una gran orquestra simfònica, quatre solistes vocals, un pianista solista i dos intèrprets de dolçaina.

Un altre bon deixeble del Mestre Garcia Julbe fou Rossend Aymí i Escolà, alumne del Seminari Diocesà, nascut a la Palma d’Ebre el 13 de juliol de 1940. Estudià la carrera de Piano al Conservatori de Tarragona i al de Saragossa. I Orgue, un any, amb Mn. Francesc Tàpies, Canonge Organista de la Seu de Tarragona, a l'orgue de la capella del Col·legi de les Teresianes de la Rambla Nova de la capital provincial, on es desplaçava des del Seminari. Estudià així mateix Harmonia, Contrapunt i Fuga amb Mn. Vicent Garcia Julbe, a Tortosa. Dirigí la Schola del Seminari com a adjunt de Mn. Vicent Garcia i hi fou també organista.

Hom li preparà una plaça de Beneficiat Organista a la Catedral de Tortosa i hi oposità davant un tribunal format per Mn. F. Tàpies, Mn. V. Garcia, Mn. Lluís Riba, Mn. Jesús Carda i Mn. Manuel Giner. S'examinà de Composició i Fuga sobre un tema de Johannes Brahms; d'Interpretació, amb obres diverses, una de les quals el Preludi i Fuga en Sol menor de J. S. Bach; d'Improvisació; i d'Acompanyament del Cant Gregorià. Els exercicis pràctics d'Interpretació, Improvisació i Acompanyament els féu a l'orgue de la Catedral tortosina.

A instància de Mn. Vicent Garcia fou enviat a perfeccionar els estudis d'Orgue a l'estranger. Podia ser a París o a Roma. I fou enviat a Roma, al Pontificio Istituto di Musica Sacra, on perfeccionà estudis d'Orgue Principal i es titulà amb Ferruccio Vignanelli durant quatre anys, es llicencià en Cant Gregorià amb els professors Rafaele Baratta i Eugène Cardine. Cursà novament i s'examinà d'Harmonia, Contrapunt i Fuga amb els mestres Armando Rienzi, Vieri Tosatti i Domenico Bartolucci, director de la Capella Sixtina.

Rossend Aymí ha estat fundador del Conservatori de Tortosa, depenent, amb els de Tarragona i Reus, de la Diputació de Tarragona, i hi és professor de Solfeig, Piano, Harmonia i Orgue. Estimant el món de l'Orgue començà a estudiar la tècnica de construcció del complex instrument i hi treballà originàriament a tall d'afeccionat. Més tard s'ha endinsat en aquest món amb professionalitat i ha construït els orgues de la parròquia de l'Assumpció de la Palma d'Ebre, de la parròquia de l'Assumpció de Flix amb la col·laboració exemplar d'un grup de jubilats, i l'orgue del Reial Monestir de la Puríssima Concepció Victòria de Tortosa, havent participat en la restauració de l'orgue de l'Arxiprestal de Morella, construït per Francesc Turull, de Cretas, i en la del de Santa Bàrbara, obra de les primeries del segle XX. El músic Rossend Aymí segueix donant abundants fruits en el camp de la música com a compositor, professor, director de corals, organista i organer. Són els fruits d'aquella bona llavor que un dia sembrà el Mestre Mn. Vicent Garcia Julbe al Seminari Diocesà.

Tornant a la Schola Cantorum del Seminari s'ha de dir que les seves actuacions anaven més enllà del propi Seminari i de la Catedral diocesana no solament per la fama que es difonia sinó també perquè es feia present en els pobles i ciutats de la Diòcesi quan hi havia alguna celebració religiosa solemne. Així, la trobem participant en les Festes Sexennals de Morella en honor de la Mare de Déu de Vallivana, algun any, com el 1952, sota la direcció de Mn. Vicent Garcia, 
interpretant diverses misses polifòniques en els diferents dies del Sexenni. ${ }^{21}$ Participà també en la inauguració i benedicció de les esglésies parroquials de Camarles, Móra d’Ebre (dirigida per Mn. I. Pérez de Heredia), Xert, Miravet, Sagrat Cor d'Amposta, església del convent de Santa Clara de Tortosa i d'altres, dirigida pel Mestre Garcia Julbe.

Trobem així mateix la Schola al Cinema Coliseum de Tortosa, el 29 de maig de 1953, participant en la vetllada d'homenatge al bisbe Moll en el Dia del Prelat amb un programa de música polifònica clàssica, religiosa i profana, i música popular regional i tortosina harmonitzada pel Mestre Garcia Julbe. ${ }^{22}$

A les cerimònies de benedicció de l'església i consagració de l'altar del Seminari Diocesà, el 12 d'octubre de 1955, la Schola hi fou protagonista amb la interpretació de la «Cantata In Dedicatione Ecclesiae», a 4 v. m., piano i orgue, de Mn. Vicent Garcia Julbe, estrenada privadament en la vetllada de Sant Aureli Agustí del 28 de'agost del mateix any.

Dies molt celebrats per la Schola Cantorum eren els d'estrena d'obres de Mn. Vicent Garcia o d'altres compositors perquè ens adonàvem del moment històric que podíem viure, de la bellesa de les obres que estrenàvem i de la gran satisfacció compartida amb el Mestre que tots els membres de la Schola sentíem. Sovint, a més, les estrenes coincidien amb dates significatives de la vida de l’Església, de la Història de la Música i del Seminari Diocesà.

Així, cal recordar l'estrena del «Magnificat», a 4 v. i. i orgue, de Mn. V. Garcia Julbe, el dia 1 de novembre de 1950, data de la definició dogmàtica de l'Assumpció de Maria. L'estrena del «Tota pulchra», a 6 v. m., de Mn. V. Garcia Julbe, l'any 1954, declarat Any Marià, Centenari de la definició dogmàtica de la Immaculada Concepció de Maria. L'estrena de l'antífona «Assumpta est», a 6 v. m., de Mn. V. Garcia Julbe, el 16 de desembre de 1958.

L'estrena del «Te Deum», a 4 i 6 v. m., cant gregorià i orgue, de Mn. V. Garcia Julbe, en ocasió de les Noces d'Argent Episcopals del Bisbe Manuel Moll, el 7 de juny de 1962. I l'estrena del Psalmus 49,II, a 4 i 6 v. m. i orgue, de Mn. V. Garcia Julbe, el 15 de desembre de 1962.

Ultra les estrenes que fèiem de moltes de les obres de Francisco Guerrero i de J. B. Comes, transcrites per Mn. V. Garcia, hi havia actuacions oportunes de la Schola Cantorum que són dignes de resaltar per llur interès històric o cultural específic. Crec que ho mereixen: 1) la del dia 15 de desembre de 1959, en què, a la vetllada de la Immaculada Assumpta, interpretàrem dos fragments importants del Drama sacro-líric «El Misteri d'Elx», amb solistes, cor i instruments, «La Vesprà» i «La Festa»; i la del 15 de desembre de 1962, en què, també a la vetllada de la Immaculada Assumpta, interpretàrem diversos fragments de la $3^{\mathrm{a}}$ part de la Cantata escènica «Atlàntida», de Manuel de Falla-Ernesto Halffter, onze mesos després de l'estrena d'una selecció en versió de concert al Gran Teatre del Liceu de Barcelona el 24 de novembre de 1961, i sis mesos després de la seva estrena al Teatre de la Scala de Milà, el 14 de juny de 1962.

D'aquella Schola Cantorum n'ha quedat un gran record, diversos programes de mà de les actuacions, partitures guardades al Seminari Diocesà -no tantes com voldríem perquè hi haurien

21. Surco, setembre de 1952, p. 2.

22. Surco, juny de 1953 , p. 1 . 
de ser totes-, en arxius d'algunes agrupacions corals, com la Coral Vicent Ripollés, de Castelló, i en arxius particulars, un d'ells el de Mn. Josep Pavia, però sobretot un gran record en la ment de tots els qui hi cantàrem.

No sé si haurà quedat i s'haurà conservat en bon estat algun dels tres discos de pedra que la Schola va gravar l'any 1954 a partir de gravacions magnetofòniques en ocasió de l'Any Marià. Un dels discos se li oferí al bisbe Manuel Moll en mostra d'agraïment per tot l'interès que posava en la formació musical dels seminaristes i en la promoció de la Schola Cantorum; un altre era en poder de Mn. Vicent Garcia Julbe; i el tercer restà al Seminari. El disc de l'Any Marià contenia en les seves dues cares A i B, respectivament, la «Cantata a la Inmaculada Concepción, de Joan Baptista Comes, del segle XVII, a 3 cors i 12 v. m., i el «Tota pulchra», a 6 v. m., de Mn. Vicent Garcia Julbe.

En tot cas, amb el profund record, n'ha quedat la nostra formació musical, l'estima i gratitud al nostre Mestre, Mn. Vicent Garcia, i al bisbe Moll, que tant va fer per la bona música al Seminari, i, en definitiva, feta pregària la nostra música, la gran lloança a Nostre Senyor Jesucrist i a la seva Santíssima Mare, la «Regina in Caelum Assumpta». Com ho fèiem amb aquell magnífic salm 46 musicat pel nostre Mestre:

«Omnes gentes, plaudite manibus;

Iubilate Deo in voce exultationis;

Quoniam Dominus excelsus, terribilis,

Rex magnus super omnem terram.

Subiecit populos nobis,

Et gentes sub pedibus nostris.

Elegit nobis haereditatem suam; Speciem Jacob quam dilexit.

Ascendit Deus in iubilo,

Et Dominus in voce tubae.

Psallite Deo nostro, psallite;

Psallite Regi nostro, psallite;

Quoniam rex omnis terrae Deus,

Psallite sapienter.

Regnabit Deus super gentes;

Deus sedet super sedem sanctam suam.

Principes populorum congregati sunt cum Deo Abraham,

Quoniam dii fortes terrae vehementer elevati sunt.

Psallite Deo nostro, psallite;

Psallite Regi nostro, psallite.» 


\section{Fonts}

- Arxiu del Seminari Diocesà. Tortosa.

Fons musical: Caixa amb partitures de Mn. Vicent Garcia Julbe. Originals i còpies.

- «Surco». Suplemento del Boletín Oficial del Obispado. Col·lecció sencera. Anys 1945-1962.

- Arxiu de la Coral Vicent Ripollés de Castelló. Castelló de la Plana.

Fons musical. Partitures de Mn. Vicent Garcia Julbe. Còpies.

- Arxiu Josep Audenis. Barcelona.

Catàleg Precios corrientes de la acreditada Fábrica de Armoniums para Capillas y Salones H.

Christofle y Etienne, rue de Charonne, París.

- Arxiu de Josep Pavia i Simó. Barcelona.

Fons musical. Partitures de Mn. Vicent Garcia Julbe. Originals i còpies.

- Informe Pavia 2001.

- Informe Riba 2001.

- Setmana Santa a la S.I.C.B. de Tortosa. Programes de mà.

\section{Bibliografia}

Alanyà i Roig, Josep, El Seminari Diocesà de Tortosa, Bisbat de Tortosa, Altés, s.l., L'Hospitalet de Llobregat, 2001.

Boix Querol, Ramón, M. Iltre. D. José María Peris Polo, O. D., Rector de Seminario (18891936), Lliçó inaugural del curs 1993-94, Seminari de Tortosa, 1994.

Corts i Blay, Ramon - Galtés i Pujol, Joan - Manent i Segimon, Albert, directors, Diccionari d'història eclesiàstica de Catalunya, 3 vols. Generalitat de Catalunya - Editorial Claret, Barcelona, 1998-2001.

Gran Enciclopèdia Catalana, 15 vols. i apèndixs, Enciclopèdia Catalana, S.A., Barcelona, 19702001.

Herrero Llidó, Juan Ramón, Programa de mà del Concierto - Homenage al M. Iltre. D. Vicente García Julbe, 1 de maig de 1984, celebrat al Seminari Diocesà deTortosa.

Pavia I Simó, Josep, La música en Cataluña en el siglo XVIII. Francesc Valls, CSIC, Barcelona, 1997. 